\title{
The Benefits of Non-Surgical Periodontal Treatment in Association with Gastric Eradication
}

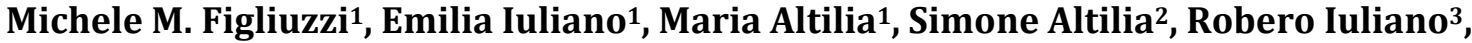 Leonzio Fortunato ${ }^{1}$}

${ }^{1}$ Department of Periodontics and Oral Sciences, Magna Graecia University, Catanzaro, Italy

${ }^{2}$ Dentistry School of the University of Tor Vergata, Roma, Italy

${ }^{3}$ Department of Gastroenterology and Digestive Endoscopy of the Pugliese-Ciaccio Hospital, Catanzaro, Italy

Email: figliuzzi@unicz.it

How to cite this paper: Figliuzzi, M.M., Iuliano, E., Altilia, M., Altilia, S., Iuliano, R. and Fortunato, L. (2020) The Benefits of Non-Surgical Periodontal Treatment in Association with Gastric Eradication. Open Journal of Stomatology, 10, 281-299. https://doi.org/10.4236/ojst.2020.1010027

Received: May 18, 2020

Accepted: October 10, 2020

Published: October 13, 2020

Copyright ( 2020 by author(s) and Scientific Research Publishing Inc. This work is licensed under the Creative Commons Attribution International License (CC BY 4.0).

http://creativecommons.org/licenses/by/4.0/ (c) (i) Open Access

\begin{abstract}
Periodontitis is a chronic degenerative disease which is inflammatory and whose bacteriological aetiology interests the hard and soft tissues supporting the dental elements. A typical characteristic of periodontitis is its correlation with other branches of medicine since periodontal disease is often associated with several other illnesses or systemic conditions which exacerbate or predispose the course of the disease. Amongst the most frequent gastroduodenal diseases are those associated with Helicobacter pylori $(\mathrm{Hp})$ infections such as acute gastritis, chronic atrophic gastritis, gastric atrophy, gastritis ulcers, dysplasia, duodenal ulcer, gastric cancer, gastric MALT-lymphoma. Transmission of the microorganism occurs through iatrogenic pathways (faecal-oral, oral-oral) and through food and water ingestion. From this the possible role of the oral cavity becomes evident as a means of transmitting the microorganism and as an extra-gastric reservoir of $\mathrm{Hp}$ which develops inside the oral plaque, the main aetiological agent of periodontal disease. Considering that in a patient affected with periodontal disease the oral cavity presents elevated indices of bacterial plaque in association with infrabony pockets one is brought to ask if it might represent a favourable habitat for $\mathrm{Hp}$ colonisation. Furthermore, another query that one might pose is whether the presence of $\mathrm{Hp}$ in the oral cavity might be the cause of relapse in gastric infections caused by Hp. Consequently, might non-surgical periodontal treatment, in association with an eradicating gastric therapy, foster decontamination of the microorganism in the oral cavity leading to a better prevention of relapse and re-infection of the gastric cavity? Could non-surgical periodontal treatment thus mean prevention of gastric diseases brought on by Helicobacter pylor? The objec-
\end{abstract}


tive of this study is therefore to evaluate the incidence of periodontal disease and oral $\mathrm{Hp}$ infection in patients affected by gastric Hpinfection and to determine the possible benefits of the association of non-surgical periodontal therapy with eradicating gastric therapy compared with treatment that involves just the eradicating gastric therapy in patients who are affected by periodontal disease and $\mathrm{Hp}$ infection.

\section{Keywords}

Helicobacter pylori, Periodontics, Non-Surgical Therapy

\section{Introduction (Periodontitis and Helicobacter pylori Infection)}

Periodontics is a branch of Odontology that studies the periodontal tissues and their correlated pathologies. Periodontitis is a disease that affects the periodontal tissues. It is a chronic degenerative disease which is inflammatory and which has bacteriological aetiology that interests the hard and soft tissues supporting the dental elements. A typical characteristic of periodontitis is its correlation with other branches of medicine since periodontal disease is often associated with several other illnesses or systemic conditions which exacerbate or predispose the course of the disease. Amongst the most frequent gastroduodenal diseases are those associated with Helicobacter pylori infections such as acute gastritis, chronic atrophic gastritis, gastric atrophy, dysplasia, with a possible evolution into gastric tumours, in some sub-groups of patients, and duodenal ulcer in other subgroups of patients. Transmission of the microorganism occurs through iatrogenic pathways (faecal-oral, oral-oral) and through food and water ingestion. From this the possible role of the oral cavity becomes evident as a means of transmitting the microorganism. In fact, Helicobacter pylori may not only be present but it can also develop in oral plaque and be a major aetiological agent of periodontal diseases. Considering that in a patient affected with periodontal disease the oral cavity presents elevated indices of bacterial plaque in association with infrabony pockets one is brought to ask if it might represent a favourable habitat for Helicobacter pylori colonisation. Furthermore, another query that one might pose is whether the presence of Helicobacter pylori in the oral cavity might be the cause of relapse in gastric infections caused by Helicobacter pylori. Consequently, might non-surgical periodontal treatment, in association with an eradicating gastric therapy, foster decontamination of the microorganism in the oral cavity leading to a better prevention of relapse and re-infection of the gastric cavity? Could non-surgical periodontal treatment thus mean prevention of gastric diseases brought on by Helicobacter pylori? The objective of this study is therefore to evaluate the incidence of periodontal disease and oral infection by Helicobacter pylori in patients affected by gastric infection caused by Helicobacter pylori, and to determine the possible benefits of the association of non-surgical 
periodontal therapy with eradicating gastric therapy compared with treatment that involves just the eradicating gastric therapy in patients who are affected by periodontal disease and infection caused by Helicobacter pylori.

\section{Infection by Helicobacter pylori}

\subsection{Description of the Bacterium}

Helicobacter pylori (from here on $\mathrm{Hp}$ ) is a gram-negative, flagellated, microaerophilic, rod-shaped bacterium that is also acid-tolerant and whose ideal habitat is the gastric mucosa. It can tolerate a very acid $\mathrm{pH}$ due to its ability to produce the enzyme urease which creates a compatible microenvironment around the bacillus. It is a very common bacterium but a good balance between the pathogenic power of the microorganism and the immune defence of the subject normally guarantees an adequate protection. It produces toxic metabolites that cause damage to cells provoking gastritis and ulcers. Although its presence in the human stomach has been noted throughout the world, the prevalence of $\mathrm{Hp}$ infection is greater in developing countries compared with already developed countries. Its discovery was the result of a fortuitous event: two scientists, Robin Warren and Barry Marshall, accidentally left some petri dishes containing gastric juices in their laboratory cupboard and a short time later noticed the formation of a patina on these dishes-these were formed by Hp colonies. If the truth be told, the bacterium itself was isolated for the first time in 1893, before the discovery in the1980s by the two Australian scientists, by Giulio Bizzozero, an Italian doctor, who noted the presence of the bacterium in dogs' stomachs but he was unable to deduce the importance of this fact. The importance of the Australians' discovery is due to the infectious attribution of $90 \%$ of duodenal ulcers and $80 \%$ of gastric ulcers.

\subsection{Ways of Transmission}

Hp spreading generally occurs by oral or oral-faecal transmission. It has been hypothesized that other ways of contagion are from contaminated water or contaminated endoscopic instruments. It has been demonstrated that $\mathrm{Hp}$ can continue to be metabolically active in running water for several days. Investigations carried out in South America have shown that the risk of infection, in children who drink water from the aqueduct is significantly higher than in those who use a private source. Proof of oral-oral contagion is in the proven presence of $\mathrm{Hp}$ in dental plaque and saliva. Furthermore, it has been hypothesized that the microorganism can reach the oral cavity after episodes of regurgitation or vomiting.

\subsection{Diagnosis}

Diagnostic methods for Hp infections can be classified as invasive (gastroscopy and biopsy) and non-invasive (breathing test, testing for the antigen in faeces, testing for antibodies in blood samples). One of the most widespread non-invasive tests is the Urea Breath Test. This is carried out by giving the patient a drink 
containing urea marked with a carbon isotope (C13 or C14) then measuring the presence of marked carbon dioxide $\left(\mathrm{CO}_{2}\right)$ released in the exhaled air. Another equally reliable non-invasive test is the testing for the antigen in faeces, called the HpSA test. Hp infections can also be diagnosed by identifying the IgG antibodies in a blood sample; this method has the disadvantage that it is impossible to distinguish between an infection in course and a previous infection thus it is inadvisable as a means of monitoring the efficaciousness of a therapy. Gastroscopy is still the main method for Hp diagnosis since it permits doctors to actually see what lesions have formed on the stomach walls and also to collect a tissue sample which can then be analysed using histological methods or the Helori Urease test. This test makes use of the characteristic ability of Hp to hydrolyse urea with the urease enzyme which is present in the membrane of the bacterium. The biopsy sample removed during the esophagogastroduodenoscopy is placed in a test tube with a solution containing urea and the degree of change in colour from yellow to red indicates positivity. The careful formulation of this test avoids false positive results given by bacteria that are also present in the biopsy sample that are different from the $\mathrm{Hp}$ bacterium and that could produce induced ureases from the substrata.

\subsection{Therapy}

In 1996 the international guidelines established the standard front-line therapy should be a course of 7 - 10 days of treatment with a protonic pump inhibitor (PPI), plus amoxicillin and clarithromycin [1]. The efficaciousness of this treatment is strongly influenced by resistance to clarithromycin; in fact, in the last ten years, a progressive decline in the rate of eradication has been noted which has gone beyond the $80 \%$ limit considered to be acceptable [2]. Several strategies have been proposed to increase the rate of eradication, amongst which the prolongation of the therapy to 14 days, or the use of four drugs (quadruple therapy containing bismuth, a sequential, concomitant or hybrid therapy) and the use of new antibiotics such as levofloxacin (Table 1). The Toronto consensus, held in 2016, decreed that the best eradicating therapy is the quadruple one over a period of 14 days with bismuth (PPI + bismuth + metronidazole + tetracycline) or without bismuth (PPI + amoxicillin + metronidazole + clarithromycin). The quadruple therapy with bismuth offers the advantage of being less influenced by resistance to antibiotics and specifically clarithromycin and metronidazole with eradication rates above 90\% [3]. Furthermore, resistance to bismuth salts has never been reported and resistance to tetracycline is still very low, making this therapy efficacious in many parts of the world. However, bismuth is not always available in some geographic areas. The quadruple therapy without bismuth, also defined as concomitant, has been shown to be superior to the standard triple treatment with a greater compliance from patients compared with the sequential treatment [4]. The triple therapy regimes are considered "restricted options", and their use, for 14 days in any case, depends on the knowledge of the local 
Table 1. Therapeutic regimes for Helicobacter pylori eradication.

\begin{tabular}{|c|c|c|}
\hline Definition of treatment & Composition & Duration \\
\hline Standard triple therapy & $\begin{array}{l}\text { - Protonic Pump inhibitor } \\
\text { - Clarithromycin } 500 \mathrm{mg} / \mathrm{bid} \\
\text { - Amoxicillin } 1 \mathrm{~g} / \mathrm{bid}^{*}\end{array}$ & $10-14$ days \\
\hline Modified Triple Therapy & $\begin{array}{l}\text { - Protonic Pump inhibitor } \\
\text { - Levofloxacin } 200 \text { or } 500 \mathrm{mg} / \mathrm{bid} \\
\text { - Amoxicillin } 1 \mathrm{~g} / \mathrm{bid}^{*}\end{array}$ & 10 days \\
\hline & $\begin{array}{l}\text { - Protonic Pump inhibitor } \\
\text { - Amoxicillin } 1 \mathrm{~g} / \mathrm{bid}^{*}\end{array}$ & 5 - 7 days \\
\hline Sequential Therapy & $\begin{array}{l}\text { Followed by } \\
\text { - Protonic Pump inhibitor } \\
\text { - } \text { Metronidazole } 500 \mathrm{mg} / \mathrm{bid} \\
\text { - } \text { Clarithromycin } 500 \mathrm{mg} / \mathrm{bid}^{\dagger}\end{array}$ & $5-7$ days \\
\hline Concomitant Therapy & $\begin{array}{l}\text { - Protonic Pump inhibitor } \\
\text { - Amoxicillin } 1 \mathrm{~g} / \mathrm{bid}^{*} \\
\text { - } \text { Metronidazole } 250 \mathrm{mg} / \mathrm{bid}^{+} \\
\text {- } \text { Clarithromycin } 500 \mathrm{mg} / \mathrm{bid}^{\dagger}\end{array}$ & 7 - 10 days \\
\hline $\begin{array}{c}\text { Quadruple Therapy with } \\
\text { Bismuth }\end{array}$ & $\begin{array}{l}\text { - Protonic Pump inhibitor } \\
\text { - Metronidazole } 250 \mathrm{mg} / \mathrm{qid} \\
\text { - Tetracycline } 250 \mathrm{mg} / \mathrm{qid}^{\ddagger} \\
\text { - Bismuth Subcitrate } 120 \mathrm{mg} / \mathrm{qid}\end{array}$ & 10 days \\
\hline & $\begin{array}{l}\text { - Protonic Pump inhibitor } \\
\text { - Amoxicillin } 1 \mathrm{~g} / \mathrm{bid}^{*}\end{array}$ & 7 days \\
\hline Hybrid Therapy & $\begin{array}{l}\text { Followed by } \\
\text { - } \text { Protonic Pump inhibitor } \\
\text { - Amoxicillin } 1 \mathrm{~g} / \mathrm{bid} \\
\text { - } \text { Metronidazole } 250 \mathrm{mg} / \mathrm{qid} \\
\text { - } \text { Clarithromycin } 500 \mathrm{mg} / \mathrm{bid}\end{array}$ & 7 days \\
\hline
\end{tabular}

epidemiologic situation, with a resistance to clarithromycin rate $<15 \%$ or an eradication rate $>85 \%$. Regimes with fluoroquinolones are not advised in the first instance but are suggested as being a "rescue therapy" should the first line therapy fail to take effect. The use of probiotics as adjuvants, considered to be promising by the European consensus of 2012, was advised against in 2016. Finally, the sequential treatment is not recommended.

\section{Association between Oral Hygiene/Periodontal State and Helicobacter pylori Infection}

An epidemiological study carried out in the United States of America based on data from the National Health and Nutrition Examination Exley III showed that periodontal disease can be associated with $\mathrm{Hp}$ infection [5]. In this study a total of 4504 patients were studied, between the ages of 20 and 59 years, all positive 
for Hp infection and with periodontal disease. The results of this study showed that periodontal pockets greater than $5 \mathrm{~mm}$ contained the bacterium and that the low periodontal health could be associated with an Hp infection. Over the years several researchers have pondered on and studied the association between periodontal disease and $\mathrm{Hp}$ infection. They obtained positive results on the presence of the bacterium in the oral cavity and above all on the association of the two diseases suggesting that the oral cavity acts as an extra-gastric reservoir [6] [7] [8] [9] [10]. Furthermore, Gürbüz et al. [7] reported a positive association between levels of dental plaque and the levels of gastric and oral $\mathrm{Hp}$. In a similar way, Butt et al. [11] reported an association between the quantity of dental plaque and the presence of $\mathrm{Hp}$ in the oral cavity, whilst Bali et al. [12] reported that inadequate oral hygiene was significantly associated with gastric Hp infection. Results showed that this bacterium was present most of all in the dental plaque of patients who presented gastric diseases that were of infectious origin, when the infection was caused by the same pathogen. Using C-reactive Protein (CRP) it was possible to assess contemporary colonisation of the gastric mucosa and the oral cavity by the same strain of Hp [13]. Helicobacter pylori adheres most to supragingival plaque, however some researchers have reported an equal presence of the bacterium in samples of supragingival and subgingival plaque [14]. Supragingival and subgingival plaque present two different microenvironments for $\mathrm{pH}$ values, for nutrient availability, for oxygen availability and for defence mechanisms in the host. Since dental plaque is a biofilm in which several bacterial species co-exist in specific interactions, Hp survival depends upon its ability to interact with other bacterial species.

\subsection{The Effects of the Gastric Eradicating Therapy on Oral Helicobacter pylori}

Several authors have investigated the effects of antibiotics on oral Hp. In their study Gebara et al. [15] examined 30 patients (15 with gingivitis and 15 with chronic periodontitis) who were positive to gastric $\mathrm{Hp}$ infection and concluded that the eradication of the bacterium, after the gastric eradication therapy, was more efficient in the stomach than in the mouth $(\mathrm{p}<0.001)$ and also that the mouths of patients with gingivitis or chronic periodontitis who also have $\mathrm{Hp}$ in the stomach can be considered to be extra-gastric reservoirs of this microorganism. Other studies, such as those by Gao et al. [16] or by Miyabayashi et al. [17], also report systemic therapy for $\mathrm{Hp}$ eradication alone has a limited effect on oral $\mathrm{Hp}$ although it is successful in treating the gastric infection. The lack of success of the systemic treatment derives from the fact that the microorganisms present in dental plaque offer a greater protection from the antimicrobial agents that are given systemically.

\subsection{The Effects of Non-Surgical Periodontal Treatment on Helicobacter pylori Infection}

Resistance of $\mathrm{Hp}$ to systemic treatment and therefore the possibility of re-infection 
of the gastric mucosa creates a need for the implementation of different treatment regimes. This has given rise to many studies that assess the benefits of non-surgical periodontal treatment in $\mathrm{Hp}$ infections. Amongst the various studies we can number that of Jia et al. [18] in which the detection rate percentage of $\mathrm{Hp}$ is less in patients who underwent non-surgical periodontal treatment and gastric eradication therapy compared with the controls who did not receive any form of periodontal therapy. Gao et al. [15] also concluded that the detection rate of $\mathrm{Hp}$ was significantly lower in the group in which gastric treatment was in association with periodontal treatment compared with the group treated with gastric therapy alone. According to this author oral Hp can determine an important gastric infection and the gastric eradication therapy, in association with non-surgical periodontal treatment, can increase the rate of long-term eradication of the microorganism in patients with gastric diseases and periodontal diseases. In another study by Zaric et al. [19], 43 patients, all positive for oral and gastric $\mathrm{Hp}$, were classified into two groups in which 21 patients received systemic treatment only and 22 received systemic treatment together with periodontal treatment. Three months after completing the treatment $77.3 \%(n=17 / 22)$ of the patients who received both the systemic and the periodontal treatment and $47.6 \%(\mathrm{n}=10 / 21)$ of the patients who received only the systemic treatment showed gastric eradication of the infection. Among the 22 patients who received both treatments Hp was detected in the dental plaque in only 6 patients $(27.3 \%)$ after completing the treatment, whilst the microorganism was detected in $66.7 \%$ $(\mathrm{n}=14)$ of the 21 patients who only received the systemic treatment. The authors also reported that eradication in the stomach coincided with eradication in the oral cavity. The periodontal treatment given to the patients in these studies consisted in a non-surgical therapy in which the microbial deposits on the surface of the teeth were removed professionally using ultrasound probes and $\mathrm{cu}$ rettes together with other means of controlling plaque such as the use of mouthwashes, after detailed motivation and education of the patient concerning how to successfully carry out oral hygiene at home. This phase of the treatment is defined as being the aetiological one and it is extremely important since this is the phase in which the microbial factors that trigger the disease are removed.

\section{The Correlation between Periodontitis and Helicobacter pylori Infection: An Experimental Study}

\subsection{The Purpose of the Study}

Several Authors consider the oral cavities of periodontopathic patients, characterised by high indices of bacterial plaque in association with infrabony pockets, to be extra-gastric reservoirs of $\mathrm{Hp}$, which is recognised as being one of the main aetiological agents for gastritis, gastric and duodenal ulcers, gastric cancer and gastric MALT-lymphoma. The lack of oral eradication of the bacterium might be at the base of the gastric recurrence. Therefore, treatment and prevention of periodontal disease, in association with gastric eradication treat- 
ment, might be fundamental for the prevention and cure of important diseases, and have a pivotal rôle in the complete eradication of a group I carcinogenic bacterium (IARC).

\subsection{The Objectives of the Study}

The objectives of this study are:

1) Assessment of the incidence of periodontal disease and oral infection by $\mathrm{Hp}$ in patients with gastric $\mathrm{Hp}$ infections;

2) Assessment of the benefits of non-surgical periodontal treatment in association with gastric eradication treatments, compared with just the gastric eradication treatment, in periodontopathic patients with $\mathrm{Hp}$ infections.

\subsection{Materials and Methods}

In this study 44 symptomatic patients with $\mathrm{Hp}$ infections, were examined after having EGDS, esophagogastroduodeonoscopies (EGDS), at the Gastroenterology and Digestive Endoscopy Unit of the Pugliese-Ciaccio Hospital in Catanzaro (S. Italy). The presence of the bacterium in the bowel was tested for using the Helori Urease test on a gastric biopsy sample collected using endoscopic biopsy forceps. In order to assess the incidence of periodontal disease the 44 patients underwent a periodontal check-up in which the presence of the disease was assessed using the following clinical parameters:

- depth of infrabony pockets;

- clinical attack level;

- gingival recession;

- percentage of bacterial plaque in the whole of the mouth;

- percentage of bleeding in the whole of the mouth;

- bleeding after probing;

- mobility.

At the same time, in order to assess the presence of an oral infection of Hp, during the periodontal check-up samples were taken of the oral plaque that were then tested using the Helori Urease test. This test uses the ability of the microorganism to hydrolyse urea using the enzyme urease present in the bacterial membrane. The presence of the bacterium in the tested matter is demonstrated by the change in colour of the solution which goes from yellow to red. On the basis of data from literature, a positive Helori Urease test result occurs when the colorimetric change happens within 20 minutes [20].

In this study, differently from the studies published by other Authors, the quadruple gastric eradication treatment, as indicated by the 2016 Toronto consensus, was used. This consisted in administering by way of mouth a protonic pump inhibitor, tetracycline $(250 \mathrm{mg})$, metronidazole $(250 \mathrm{mg})$, and bismuth subcitrate $(120 \mathrm{mg})$. The non-surgical periodontal treatment, after instructing and motivating the patient in how to carry out oral hygiene at home, consisted in several phases of detoxification of the oral cavity: 
- premedication with mouthwashes containing $20 \%$ clorexidine for one week prior to treatment;

- scaling;

- root planing.

In order to assess the benefits of the non-surgical periodontal treatment associated with the gastric treatment, compared with the treatment involving only gastric treatment, the patients with oral $\mathrm{Hp}$ and periodontal disease were divided randomly into two groups: the case study group and the control group. The case study group was treated with eradicating gastric therapy and non-surgical periodontal treatment; the control group was treated with just the eradicating gastric therapy. Based on the gravity of the disease and the compliance of the patient several more scaling and root planning sittings were carried out. Assessment of the effective eradication of the infection in the gastric area and the complete healing of the disease was carried out in two ways: a repeat EGDS (for those with gastric lesions this was carried out 30 days after the first investigation and for those with duodenal and/or oesophageal lesions after 60 - 90 days) or by screening for the antigen in faeces. The presence of plaque, assessment of periodontal disease and oral infection by Hp were evaluated in check-up visits 1, 3 and 6 months after having completed the detoxification therapy and maintenance therapy of the mouth using the Helori Urease test.

\subsection{Results}

From the general anamnesis $9 \%$ of patients were found to be recidivists for gastric Hp infection. Subsequent to taking samples of bacterial plaque and periodontal assessment the following results were found (Figure 1):

- $14 \%$ (6 patients) did not have Hp infection in the oral cavity but they did have periodontal disease;

- $4 \%$ (2 patients) did not have periodontal disease but they did have oral Hp infections;

- $9 \%$ (4 patients) had neither periodontal disease nor Hp infection;

- $73 \%$ (32 patients) had $\mathrm{Hp}$ infection of the oral cavity and periodontal disease.

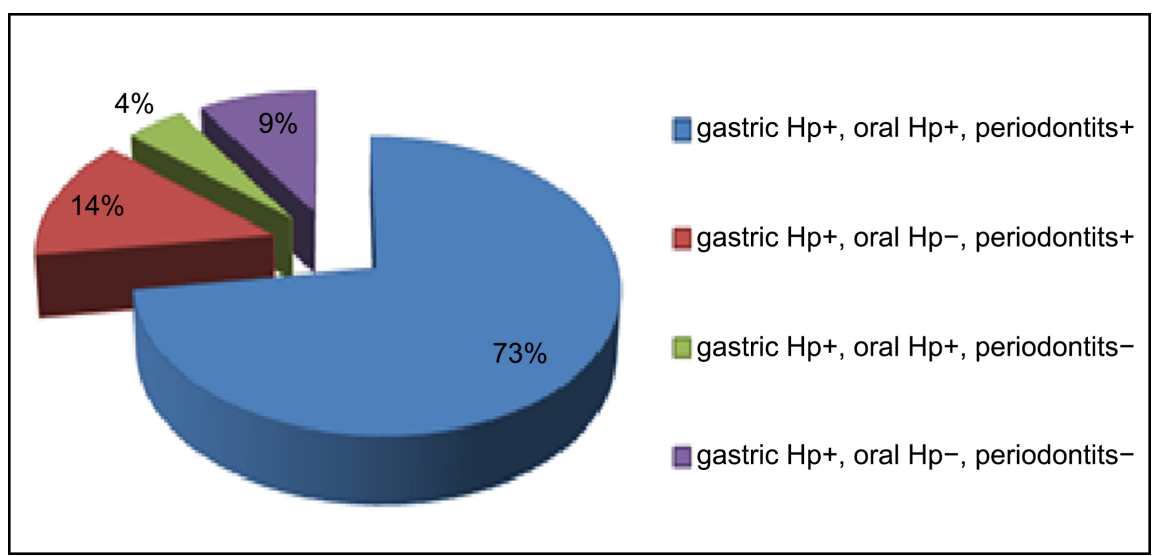

Figure 1. Results of bacterial plaque assessment. 
From this data it is possible to conclude that a greater number of patients (73\%) had an oral infection in association with periodontal disease and the patients who were recidivists for $\mathrm{Hp}$ infection (9\%) had periodontal disease and were positive for oral $\mathrm{Hp}$ infection. The difference between the group of patients that had periodontal disease and were also oral Hp positive (73\%) and the group of patients that had periodontal disease but were oral Hp negative (14\%) is that:

- In the first group we found $25 \%$ of patients with stage I of the disease, $43.7 \%$ with stage II and $31.25 \%$ with stage III (Figure 2). Furthermore, $62.5 \%$ presented a grade A level of disease and $37.5 \%$ grade B level (Figure 3 ).

- In the second group we found $50 \%$ of the patients had stage I of the disease, $34 \%$ stage II and $16 \%$ stage III (Figure 4 ) and $84 \%$ presented a grade A level of disease whilst $16 \%$ presented a grade B level (Figure 5).

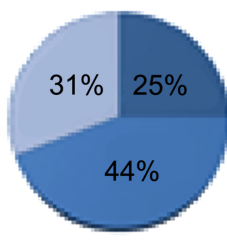

Stage I

Stage II

Stage III

Patients with periodontal disease positive for oral HP

Figure 2. Patients with periodontal disease positive for oral $\mathrm{Hp}$.

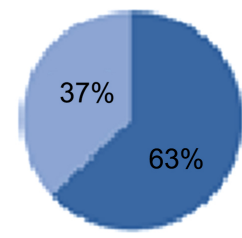

Grade A

Grade B

Patients with periodontal disease positive for oral $\mathrm{Hp}$ infection

Figure 3. Patients with periodontal disease positive for oral $\mathrm{Hp}$.

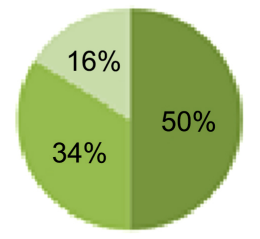

Stage I

E Stage II

- Stage III

Patients with periodontal disease negative for oral HP

Figure 4. Patients with periodontal disease negative for oral $\mathrm{Hp}$. 


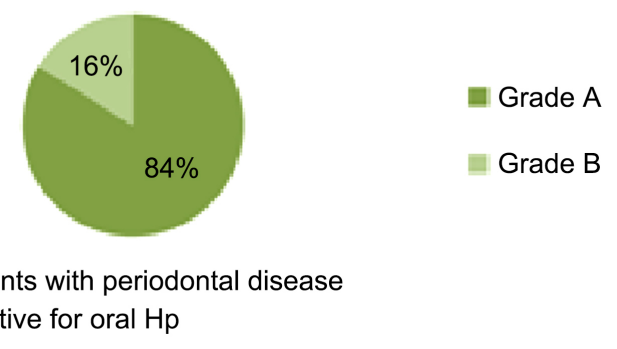

Figure 5. Patients with periodontal disease negative for oral Hp.

At the beginning and end of the period of treatment and follow-up observation the case group results were as follows (Table 2, Table 3):

- Reduction of the Probe Depth (PD);

- Increase in the Clinical Level of Attack (CAL);

- Reduction in the percentage of bacterial plaque in the whole of the mouth Full Mouth Plaque Score (FMPS);

- Reduction in/absence of percentage of bleeding in the whole of the mouth Full Mouth Bleeding Score (FMBS);

- Increase in the recession (REC);

- Negative results for the Helori Urease test.

Contrary to the group of case studies the control group results showed the following results (Table 4, Table 5):

- Unaltered probing depth (PD);

- Equal levels of Clinical Attack (CAL);

- Unaltered percentage of bacterial plaque in the whole of the mouth-Full Mouth Plaque Score (FMPS);

- Unaltered percentage of bleeding in the whole of the mouth-Full Mouth Bleeding Score (FMBS);

- Unaltered recessions (REC);

- Positive results for oral Helori Urease tests.

After carrying out gastroenterological tests the results showed that all the patients of the case study group and of the control group had achieved gastric eradication through the quadruple gastric eradication therapy.

\subsection{Statistical Analysis}

In order to assess the statistical significance of the results a Student t-test was carried out. The first analysis carried out was to assess the statistical significance connected with the initial and final values of the two groups. After this a Student t-test was carried out on paired patients in which the initial and final values of the case group and the initial and final values of the control group were compared. From the analysis carried out the results of the group case were shown to be statistically significant since $\mathrm{p}<0.05$ (Table 6). Since the treatment under assessment was not carried out in the control group, the objective of the study was 
Table 2. Initial periodontal values for the case group.

\begin{tabular}{ccccccc}
\hline Casi & PD (mm) & CAL (mm) & FMPS $(\%)$ & FMBS (\%) & REC & $\begin{array}{c}\text { Oral Helori } \\
\text { Urease Test }\end{array}$ \\
\hline 1 & 2.8 & -3 & $85 \%$ & $88 \%$ & -4 & Positive \\
2 & 1 & -1.1 & $92 \%$ & $87 \%$ & -2 & Positive \\
3 & 1.3 & -1.3 & $73 \%$ & $79 \%$ & -2 & Positive \\
4 & 1.1 & -1.1 & $59 \%$ & $67 \%$ & -2 & Positive \\
5 & 1.2 & -1.2 & $65 \%$ & $55 \%$ & -1 & Positive \\
6 & 1.8 & -1.8 & $85 \%$ & $86 \%$ & 0 & Positive \\
7 & 0.9 & -0.9 & $63 \%$ & $66 \%$ & 0 & Positive \\
8 & 1.2 & -1.3 & $70 \%$ & $73 \%$ & -2 & Positive \\
9 & 2.8 & -3 & $85 \%$ & $88 \%$ & -4 & Positive \\
10 & 1 & -1.1 & $92 \%$ & $87 \%$ & -2 & Positive \\
11 & 1.3 & -1.3 & $73 \%$ & $79 \%$ & -2 & Positive \\
12 & 1.1 & -1.1 & $59 \%$ & $67 \%$ & -2 & Positive \\
13 & 1.2 & -1.2 & $65 \%$ & $55 \%$ & -1 & Positive \\
14 & 1.8 & -1.8 & $85 \%$ & $86 \%$ & 0 & Positive \\
15 & 0.9 & -0.9 & $63 \%$ & $66 \%$ & 0 & Positive \\
16 & 1.2 & -1.3 & $70 \%$ & $73 \%$ & -2 & Positive \\
\hline
\end{tabular}

Table 3. Final periodontal values for the case group.

\begin{tabular}{|c|c|c|c|c|c|c|}
\hline Case & $\mathrm{PD}(\mathrm{mm})$ & CAL (mm) & FMPS (\%) & FMBS (\%) & REC & $\begin{array}{l}\text { Oral Helori } \\
\text { Urease Test }\end{array}$ \\
\hline 1 & 1.3 & -1.8 & $0 \%$ & $14 \%$ & -4 & Negative \\
\hline 2 & 0.4 & -0.7 & $1 \%$ & $6 \%$ & -3 & Negative \\
\hline 3 & 0.3 & -0.5 & $0 \%$ & $0 \%$ & -2 & Negative \\
\hline 4 & 0.2 & -0.4 & $2 \%$ & $0 \%$ & -2 & Negative \\
\hline 5 & 0.4 & -0.6 & $0 \%$ & $3 \%$ & -2 & Negative \\
\hline 6 & 0.7 & -0.9 & $4 \%$ & $4 \%$ & -2 & Negative \\
\hline 7 & 0.4 & -0.5 & $0 \%$ & $0 \%$ & -2 & Negative \\
\hline 8 & 0.3 & -0.6 & $2 \%$ & $2 \%$ & -2 & Negative \\
\hline 9 & 1.3 & -1.8 & $0 \%$ & $14 \%$ & -4 & Negative \\
\hline 10 & 0.4 & -0.7 & $1 \%$ & $6 \%$ & -3 & Negative \\
\hline 11 & 0.3 & -0.5 & $0 \%$ & $0 \%$ & -2 & Negative \\
\hline 12 & 0.2 & -0.4 & $2 \%$ & $0 \%$ & -2 & Negative \\
\hline 13 & 0.4 & -0.6 & $0 \%$ & $3 \%$ & -2 & Negative \\
\hline 14 & 0.7 & -0.9 & $4 \%$ & $4 \%$ & -2 & Negative \\
\hline 15 & 0.4 & -0.5 & $0 \%$ & $0 \%$ & -2 & Negative \\
\hline 16 & 0.3 & -0.6 & $2 \%$ & $2 \%$ & -2 & Negative \\
\hline
\end{tabular}


Table 4. Initial periodontal values for the control group.

\begin{tabular}{ccccccc}
\hline Control & PD (mm) & CAL (mm) & FMPS (\%) & FMBS (\%) & REC & $\begin{array}{c}\text { Oral Helori } \\
\text { Urease Test }\end{array}$ \\
\hline 1 & 1.4 & -1.5 & $76 \%$ & $92 \%$ & -2 & Positive \\
2 & 0.8 & -0.8 & $76 \%$ & $81 \%$ & 0 & Positive \\
3 & 1.8 & -1.9 & $80 \%$ & $83 \%$ & -1 & Positive \\
4 & 1.4 & -1.4 & $76 \%$ & $78 \%$ & 0 & Positive \\
5 & 1.3 & -1.3 & $46 \%$ & $74 \%$ & 0 & Positive \\
6 & 4.5 & -4.8 & $78 \%$ & $78 \%$ & -2 & Positive \\
7 & 1.9 & -2 & $81 \%$ & $81 \%$ & -2 & Positive \\
8 & 0.7 & -0.8 & $59 \%$ & $58 \%$ & 0 & Positive \\
9 & 1.4 & -1.5 & $76 \%$ & $92 \%$ & -2 & Positive \\
10 & 0.8 & -0.8 & $76 \%$ & $81 \%$ & 0 & Positive \\
11 & 1.8 & -1.9 & $80 \%$ & $83 \%$ & -1 & Positive \\
12 & 1.4 & -1.4 & $76 \%$ & $78 \%$ & 0 & Positive \\
13 & 1.3 & -1.3 & $46 \%$ & $74 \%$ & 0 & Positive \\
14 & 4.5 & -4.8 & $78 \%$ & $78 \%$ & -2 & Positive \\
15 & 1.9 & -2 & $81 \%$ & $81 \%$ & -2 & Positive \\
16 & 0.7 & -0.8 & $59 \%$ & $58 \%$ & 0 & Positive \\
\hline
\end{tabular}

Table 5. Final periodontal values for the control group.

\begin{tabular}{|c|c|c|c|c|c|c|}
\hline Control & $\mathrm{PD}(\mathrm{mm})$ & CAL (mm) & FMPS (\%) & FMBS (\%) & REC & $\begin{array}{l}\text { Oral Helori } \\
\text { Urease Test }\end{array}$ \\
\hline 1 & 1.5 & -1.5 & $77 \%$ & $94 \%$ & -2 & Positive \\
\hline 2 & 0.8 & -0.8 & $70 \%$ & $81 \%$ & 0 & Positive \\
\hline 3 & 1.8 & -1.9 & $80 \%$ & $85 \%$ & -1 & Positive \\
\hline 4 & 1.4 & -1.4 & $76 \%$ & $78 \%$ & 0 & Positive \\
\hline 5 & 1.3 & -1.3 & $46 \%$ & $74 \%$ & 0 & Positive \\
\hline 6 & 4.5 & -4.8 & $78 \%$ & $80 \%$ & -2 & Positive \\
\hline 7 & 1.9 & -2 & $81 \%$ & $81 \%$ & -2 & Positive \\
\hline 8 & 0.7 & -0.8 & $58 \%$ & $58 \%$ & 0 & Positive \\
\hline 9 & 1.5 & -1.5 & $77 \%$ & $94 \%$ & -2 & Positive \\
\hline 10 & 0.8 & -0.8 & $70 \%$ & $81 \%$ & 0 & Positive \\
\hline 11 & 1.8 & -1.9 & $80 \%$ & $85 \%$ & -1 & Positive \\
\hline 12 & 1.4 & -1.4 & $76 \%$ & $78 \%$ & 0 & Positive \\
\hline 13 & 1.3 & -1.3 & $46 \%$ & $74 \%$ & 0 & Positive \\
\hline 14 & 4.5 & -4.8 & $78 \%$ & $80 \%$ & -2 & Positive \\
\hline 15 & 1.9 & -2 & $81 \%$ & $81 \%$ & -2 & Positive \\
\hline 16 & 0.7 & -0.8 & $58 \%$ & $58 \%$ & 0 & Positive \\
\hline
\end{tabular}


to achieve a result that was not statistically significant and therefore $\mathrm{p}>0.05$. From the statistical analysis we can conclude that in the control group there was no difference in the initial and final values (Table 7).

After this, in order to assess the statistical significance of the results of the case group compared with the control group, a Student t-test for non-paired values was carried out. A statistical significance was obtained for every periodontal value since $\mathrm{p}<0.05$ (Tables $8-12$ ). We can therefore deduce that the results achieved with the therapy used in the case study group compared with the results in the control group are statistically significant.

Table 6. Student t-test for paired samples in the case group before and after gastric and periodontal treatment-Test for paired patients.

\begin{tabular}{|c|c|c|c|c|c|c|c|c|c|}
\hline \multirow{3}{*}{ Pair } & & \multicolumn{5}{|c|}{ Difference per pair-Case group } & \multirow{3}{*}{$\mathrm{t}$} & \multirow{3}{*}{ df } & \multirow{3}{*}{$\begin{array}{c}\text { Sig. } \\
(2-\text { code })\end{array}$} \\
\hline & & \multirow{2}{*}{ Average } & \multirow{2}{*}{$\begin{array}{l}\text { Standard } \\
\text { Deviation }\end{array}$} & \multirow{2}{*}{$\begin{array}{c}\text { Standard } \\
\text { Average Error. }\end{array}$} & \multicolumn{2}{|c|}{$\begin{array}{l}\text { Confidence Interval for the } \\
\text { difference at } 95 \%\end{array}$} & & & \\
\hline & & & & & Inferior & Superior & & & \\
\hline 1 & $\begin{array}{l}\text { initial PDmm } \\
\text { final PDmm }\end{array}$ & 0.9125 & 0.2986 & 0.0747 & 0.7534 & 1.0716 & 12.223 & 15 & 0.000 \\
\hline 2 & $\begin{array}{l}\text { Initial CALmm } \\
\text { final CALmm }\end{array}$ & -0.7125 & 0.2553 & 0.0638 & -0.8485 & -0.5765 & -11.164 & 15 & 0.000 \\
\hline 3 & $\begin{array}{l}\text { initial FMPS } \\
\text { final FMPS }\end{array}$ & $72.87500 \%$ & $11.41271 \%$ & $2.85318 \%$ & $66.79359 \%$ & $78.95641 \%$ & 25.542 & 15 & 0.000 \\
\hline 5 & $\begin{array}{l}\text { initial REC } \\
\text { final REC }\end{array}$ & 0.7500 & 0.8563 & 0.2141 & 0.2937 & 1.2063 & 3.503 & 15 & 0.003 \\
\hline
\end{tabular}

Table 7. Student t-test for paired samples in the control group before and after gastric treatment-Test for paired patients.

\begin{tabular}{|c|c|c|c|c|c|c|c|c|c|}
\hline \multirow{3}{*}{ Pair } & & \multicolumn{5}{|c|}{ Difference per pair-Control group } & \multirow{3}{*}{$\mathrm{t}$} & \multirow{3}{*}{ df } & \multirow{3}{*}{$\begin{array}{c}\text { Sig. } \\
\text { (2-code) }\end{array}$} \\
\hline & & \multirow{2}{*}{ Average } & \multirow{2}{*}{$\begin{array}{l}\text { Standard } \\
\text { Deviation }\end{array}$} & \multirow{2}{*}{$\begin{array}{c}\text { Standard } \\
\text { Average Error }\end{array}$} & \multicolumn{2}{|c|}{$\begin{array}{l}\text { Confidence Interval for the } \\
\text { difference at } 95 \%\end{array}$} & & & \\
\hline & & & & & Inferior & Superior & & & \\
\hline 1 & $\begin{array}{l}\text { initial PDmm } \\
\text { final PDmm }\end{array}$ & -0.0125 & 0.0342 & 0.0085 & -0.0307 & 0.0057 & -1.464 & 15 & 0.164 \\
\hline 2 & $\begin{array}{l}\text { initial CALmm } \\
\text { final CALmm }\end{array}$ & 0.0063 & 0.0250 & 0.0063 & -0.0071 & 0.0196 & 1.000 & 15 & 0.333 \\
\hline 3 & $\begin{array}{l}\text { initial FMPS } \\
\text { final FMPS }\end{array}$ & $0.62500 \%$ & $2.12525 \%$ & $0.53131 \%$ & $-0.50746 \%$ & $1.75746 \%$ & 1.176 & 15 & 0.258 \\
\hline 4 & $\begin{array}{l}\text { initial FMBS } \\
\text { final FMBS }\end{array}$ & $-0.06250 \%$ & $0.25000 \%$ & $0.06250 \%$ & $-0.19572 \%$ & $0.07072 \%$ & -1.000 & 15 & 0.333 \\
\hline 5 & $\begin{array}{l}\text { initial REC } \\
\text { final REC }\end{array}$ & -0.063 & 0.250 & 0.063 & -0.196 & 0.071 & -1.000 & 15 & 0.333 \\
\hline
\end{tabular}


Table 8. Student t-test for non-paired samples. Comparison between PD for case studies and PD for controls.

\begin{tabular}{ccc}
\hline Dataset & 1 & 2 \\
\hline Numerousness of sample & 16 & 16 \\
Average & 0.5000 & 1.7375 \\
Standard Deviation & 0.3425 & 1.1535 \\
$t$ & 4.1138 & \\
Degree of freedom & 30 & \\
P (significance level) & $\mathbf{0 . 0 0 0 3}$ & \\
\hline
\end{tabular}

Table 9. Student t-test for non-paired samples. Comparison between CAL for case studies and CAL for controls.

\begin{tabular}{ccc}
\hline Dataset & 1 & 2 \\
\hline Numerousness of sample & 16 & 16 \\
Average & -0.7500 & -1.8125 \\
Standard Deviation & 0.4351 & 1.2409 \\
$T$ & 3.2320 & \\
Degree of freedom & $\mathbf{3 0}$ & \\
P (significance level) & $\mathbf{0 . 0 0 3 0}$ & \\
\hline
\end{tabular}

Table 10. Student t-test for non-paired samples. Comparison between FMPS for case studies and FMPS for controls.

\begin{tabular}{ccc}
\hline Dataset & 1 & 2 \\
\hline Numerousness of sample & 16 & 16 \\
Average & 0.0113 & 0.7075 \\
Standard Deviation & 0.0141 & 0.1203 \\
$T$ & $\mathbf{2 2 . 9 9 2 5}$ & \\
Degree of freedom & $\mathbf{3 0}$ & \\
P (significance level) & $\mathbf{0 . 0 0 0 0}$ & \\
\hline
\end{tabular}

Table 11. Student t-test for non-paired samples. Comparison between FMBS for case studies and FMBS for controls.

\begin{tabular}{ccc}
\hline Dataset & 1 & 2 \\
\hline Numerousness of sample & 16 & 16 \\
Average & 0.0363 & 0.7888 \\
Standard Deviation & 0.0456 & 0.0991 \\
$t$ & $\mathbf{2 7 . 5 8 8 8}$ & \\
Degree of freedom & $\mathbf{3 0}$ & \\
P (significance level) & $\mathbf{0 . 0 0 0 0}$ & \\
\hline
\end{tabular}


Table 12. Student t-test for non-paired samples. Comparison between REC for case studies and REC for controls.

\begin{tabular}{ccc}
\hline Dataset & 1 & 2 \\
\hline Numerousness of sample & 16 & 16 \\
Average & -2.3750 & -0.8750 \\
Standard Deviation & 0.7188 & 0.9574 \\
$t$ & 5.0116 & \\
Degree of freedom & 30 & \\
P (significance level) & 0.0000 & \\
\hline
\end{tabular}

\subsection{Conclusions}

The first phase of the study showed that $73 \%$ of the patients with gastric Hp infection also had periodontal disease and a positive Oral Helori Urease Test and this group included $9 \%$ of the patients who were recidivistic for gastric infection. Furthermore, in the patients with periodontitis and positive oral Hp the severity of the periodontal disease was greater both in terms of the stage and the grade compared with the group of patients with periodontal disease and a negative oral Hp result. These results confirm the theory suggested by a number of Authors according to whom there is a high incidence of periodontal disease in patients with gastric Hp infections which can be transmitted orally since the bacterium finds a favourable habitat for antibiotic resistance in the oral cavity of periodontal patients. In fact, the Hp bacterium adheres to the periodontal pathogenic bacteria such as Fusobacterium species (Fusobacterium nucleatum), Porphyromonas gingivalis and Forsythus Bacteroides which confer resistance to systemic antibiotic therapies. Low levels of oral hygiene and therefore low levels of periodontal health are associated with the presence of oral and gastric Hp. Therefore, in the majority of cases, patients with a gastric $\mathrm{Hp}$ infection present periodontal disease with oral infection by $\mathrm{Hp}$ and they are exposed to the risk of recidivist infection despite gastric eradication therapy.

In the second phase of the investigation we obtained gastric eradication by using the quadruple eradication therapy both for the case study group and for the control group. Six months after the non-surgical periodontal treatment together with the gastric eradication treatment in the patients that made up the case study group, we obtained the following results:

- Statistically significant improvement of periodontal disease $(\mathrm{p}<0.05)$;

- Negative results for the oral Helori Urease Test in $100 \%$ of patients.

This is an indication that gastric therapy is effective for the gastric infection but not for the oral one and this is because of the protection conferred on the bacterium by the periodontal oral biofilm.

In the group of control patients, the results were as follows:

- Lack of improvement of periodontal disease ( $p>0.05)$;

- Positive results for the oral Helori Urease test in $100 \%$ of patients. 
We can therefore say that the quadruple gastric eradication therapy is effective in the gastric eradication of the bacterium but not for oral eradication. For this non-surgical periodontal treatment is necessary. Thus, the presence of the bacterium in the oral cavity, in cases such as the control group, exposes the patients to a risk of recidivism. We can therefore conclude, in the light of the statistically significant results $(\mathrm{p}<0.05)$, that the benefit of non-surgical periodontal treatment, in association with gastric treatment, is that we obtain a control of and an improvement in the periodontal status which allows for the total eradication of the bacterium.

\section{Discussion}

This study is the fruit of several queries regarding the correlation between two diseases: periodontitis and gastric Hp infection. We asked ourselves questions about the rôle of the oral cavity, about its function as an extra-gastric reservoir for Hp bacteria, about the importance of non-surgical periodontal treatment in order to determine prevention as well as improvement of the gastric treatment of a group I carcinogenic bacterium that is responsible for gastritis, and gastric and duodenal ulcers.

In the light of the results obtained, and the literature that supports them, we can affirm that there is a correlation between periodontal disease and gastric $\mathrm{Hp}$ infection, that the oral cavity of periodontally diseased patients with gastric infection can be an extra-gastric reservoir of $\mathrm{Hp}$ and that this state is associated with patients who have the most severe periodontal disease both in terms of degree and stage. This is caused by the adhesion of $\mathrm{Hp}$ to the periodontal pathogen bacteria. Accordingly, a greater severity of periodontitis predisposes a greater adhesion of the bacterium. Consequently, gastric eradication therapy is insufficient for achieving a complete eradication of the bacterium which enjoys antibiotic resistance conferred by its aggregation with the bacteria that are responsible for periodontal disease. On the basis of the statistically significant results achieved with the case study group compared with the results for the control group, this study suggests inserting non-surgical periodontal treatment into the protocol for the management of Hp infections.

We cannot say whether the "primum movens" of this correlation is the periodontal disease which offers an ideal habitat for colonisation by Hp, which then infects the gastrointestinal apparatus, or whether it is the gastric infection that, after an episode of gastrointestinal reflux, determines the oral colonisation of patients with periodontal disease. However, from this study we can attribute the rôle of extra-gastric reservoir for $\mathrm{Hp}$ from where the bacterium can spread and re-infect the stomach thus causing recidivism to the oral cavity of patients with periodontal disease.

Treatment of periodontal disease, as is widely known, produces significant benefits in the control and improvement of many diseases such as diabetes, respiratory diseases, cardio-vascular diseases and reduces the risk of pre-term births 
and underweight new-borns. In the same way, in the light of the data we obtained, we can assert that non-surgical periodontal treatment produces noticeable improvement in the eradication of gastric $\mathrm{Hp}$ infections. Thus, it is possible to reply to the previously posed queries by saying that control of periodontal disease, through non-surgical periodontal treatment, allows oral eradication of $\mathrm{Hp}$ infection and prevents diseases that are connected to the same.

\section{Conflicts of Interest}

The authors declare no conflicts of interest regarding the publication of this paper.

\section{References}

[1] (1997) Current European Concepts in the Management of Helicobacter pylori Infection. The Maastricht Consensus Report. European Helicobacter pylori Study Group. Gut, 41, 8-13.

[2] Rimbara, E., Fishbach, L.A. and Graham, D.Y. (2011) Optimal Therapy for Helicobacter pylori Infections. Nature Reviews Gastroenterology \& Hepatology, 8, 79-88. https://doi.org/10.1038/nrgastro.2010.210

[3] Malfertheiner, P., Bazzoli, F., Delchier, J.C., Celiñski, K., et al. (2011) Helicobacter pylori Eradication with a Capsule Containing Bismuth Subcitrate Potassium, Metronidazole, and Tetracycline Given with Omeprazole versus Clarithromycin-Based Triple Therapy: A Randomised, Open-Label, Non-Inferiority, Phase 3 Trial. The Lancet, 377, 905-913. https://doi.org/10.1016/S0140-6736(11)60020-2

[4] Wu, D.-C., et al. (2010) Sequential and Concomitant Therapy with Four Drugs Is Equally Effective for Eradication of $H$. pylori Infection. Clinical Gastroenterology and Hepatology, 8, 36-41.

[5] Dye, B.A., Kruszon-Moran, D. and McQuillan, G. (2002) The Relationship between Periodontal Disease Attributes and Helicobacter pylori Infection among Adults in the United States. American Journal of Public Health, 92, 1809-1815. https://doi.org/10.2105/AJPH.92.11.1809

[6] Umeda, M., Kobayashi, H., Takeuchi, Y., Hayashi, J., MorotomeHayashi, Y., Yano, K., Aoki, A., Ohkusa, T. and Ishikawa, I. (2003) High Prevalence of Helicobacter pylori Detected by PCR in the Oral Cavities of Periodontitis Patients. Journal of Periodontology, 74, 129-134. https://doi.org/10.1902/jop.2003.74.1.129

[7] Gürbüz, A.K., Ozel, A.M., Yazgan, Y., Celik, M. and Yildirim, S. (2003) Oral Colonization of Helicobacter pylori: Risk Factors and Response to Eradication Therapy. Southern Medical Journal, 96, 244-247. https://doi.org/10.1097/01.SMJ.0000051069.50950.2B

[8] Al Asqah, M., Al Hamoudi, N., Anil, S., Al Jebreen, A. and Al-Hamoudi, W.K. (2009) Is the Presence of Helicobacter pylori in Dental Plaque of Patients with Chronic Periodontitis a Risk Factor for Gastric Infection? Canadian Journal of Gastroenterology, 23, 177-179. https://doi.org/10.1155/2009/950527

[9] Choudhury, C.R., Choudhury, A.D., Alam, S., Markus, A.F. and Tanaka, A. (2003) Presence of H. pylori in the Oral Cavity of Betelquid ("Paan") Chewers with Dyspepsia: Relationship with Periodontal Health. Public Health, 117, 346-347. https://doi.org/10.1016/S0033-3506(03)00104-5

[10] Sambashivaiah, S., Bilichodmath, S., Nanjaiah, N. and Kulal, R. (2011) Helicobacter 
pylori in Periodontal Pockets of Chronic Periodontitis Patients with and without Type II Diabetes Mellitus: A Randomized Controlled Trial. Microbiological Research, 2, e12. https://doi.org/10.4081/mr.2011.e12

[11] Butt, A.K., Khan, A.A., Khan, A.A., Izhar, M., Alam, A., Shah, S.W. and Shafqat, F. (2002) Correlation of Helicobacter pylori in Dental Plaque and Gastric Mucosa of Dyspeptic Patients. Journal of Pakistan Medical Association, 52, 196-200.

[12] Bali, D., Rosamma, J. and Bali, A. (2010) The Association of Dental Plaque and Helicobacter pylori Infection in Dyspeptic Patients Undergoing Endoscopy. Journal of Clinical and Diagnostic Research, 4, 3614-3621.

[13] Bharath, T.S., Reddy, M.S., Dhanapal, R., Raj Kumar, N.G., Neeladri Raju, P. and Saraswathi, T. (2014) Molecular Detection and Correlation of Helicobacter pylori in Dental Plaque and Gastric Biopsies of Dyspeptic Patients. Journal of Oral and Maxillofacial Pathology, 18, 19-24. https://doi.org/10.4103/0973-029X.131885

[14] Gebara, E.C., Pannuti, C., Faria, C.M., Chehter, L., Mayer, M.P. and Lima, L.A. (2004) Prevalence of Helicobacter pylori Detected by Polymerase Chain Reaction in the Oral Cavity of Periodontitis Patients. Oral Microbiology and Immunology, 19, 277-280. https://doi.org/10.1111/j.1399-302X.2004.00153.X

[15] Gebara, E.C., Faria, C.M., Pannuti, C., Chehter, L., Mayer, M.P. and Lima, L.A. (2006) Persistence of Helicobacter pylori in the Oral Cavity after Systemic Eradication Therapy. Journal of Clinical Periodontology, 33, 329-333. https://doi.org/10.1111/j.1600-051X.2006.00915.x

[16] Gao, J., Li, Y., Wang, Q., Qi, C. and Zhu, S. (2011) Correlation between Distribution of Helicobacter pylori in Oral Cavity and Chronic Stomach Conditions. Journal of Huazhong University of Science and Technology_Medical Science, 31, 409-412. https://doi.org/10.1007/s11596-011-0391-6

[17] Miyabayashi, H., Furihata, K., Shimizu, T., Ueno, I. and Akamatsu, T. (2000) Influence of Oral Helicobacter pylori on the Success of Eradication Therapy against Gastric Helicobacter pylori. Helicobacter, 5, 30-37. https://doi.org/10.1046/j.1523-5378.2000.00004.x

[18] Jia, C.L., Jiang, G.S., Li, C.H. and Li, C.R. (2009) Effect of Dental Plaque Control on Infection of Helicobacter pylori in Gastric Mucosa. Journal of Periodontology, 80, 1606-1609. https://doi.org/10.1902/jop.2009.090029

[19] Zaric, S., Bojic, B., Jankovic, L., Dapcevic, B., Popovic, B., Cakic, S. and Milasin, J. (2009) Periodontal Therapy Improves Gastric Helicobacter pylori Eradication. Journal of Dental Research, 88, 946-950. https://doi.org/10.1177/0022034509344559

[20] Anand, P.S., Kamath, K.P. and Anil, S. (2014) Role of Dental Plaque, Saliva and Periodontal Disease in Helicobacter pylori Infection. World Journal of Gastroenterology, 20, 5639-5653. 